\title{
The Revision of Regulation 1049/2001: Public Access Deadlocked for a Decade
}

\author{
Mehmet Aktas ${ }^{1}$
}

\begin{abstract}
The 1049/2001 regulation on access to Commission, European Parliament and Council documents, was due to be revised a decade ago. The revision process began with a proposal by the Commission in 2008. However, the negative response of the European Parliament signalled, what came to be a deadlocked process. This paper aims to unearth the underlying reasons for this deadlock by comparing the proposal of the Commission to the resolution adopted by the European Parliament in response to it. The resulting differences in both institutions' positions will serve to clarify their underlying motives for rejecting each other's proposals. The ultimate objective of this chapter is to shed light on the Commission and the European Parliament's attitudes towards transparency and the right to public access to documents within the European Union.
\end{abstract}

\section{Introduction}

On the $21^{\text {st }}$ of May 2013, a parliamentary session was held to discuss the deadlock on the revision of Regulation (EC) No 1049/2001 on public access to European Parliament, Council and Commission documents (hereinafter 'Regulation 1049/2001' or 'the Regulation'). The Maltese Commissioner Tonio Borg was present on behalf of the Commission. During this conference, a somewhat peculiar incident occurred which reflects the situation in which the process of the revision of Regulation 1049/2001 has been for approximately a decade now. MEP In't Veld counterargued the claim made by MEP Sommer, that EU Citizens would be affected by, and would suffer if the scope of Regulation 1049/2001 was to be reduced. Then she went on to explain how access to documents was important to ensure transparency and in turn how transparency was crucial in making EU institutions accountable to EU citizens and lastly how this would increase the democratic credentials of the EU institutions.

Then, Ms. In't Veld turned to the Commission representative, to address him. However, it turned out that Borg had not been listening to Ms. In't Veld. He had removed the headphone providing translation, and had not listened to the speaker, suggesting he did not care about what the MEP thought and said on the issue. In't Veld was not amused and said: 'Chair, maybe you can ask or point out to the Commission that we're having a debate here. If they care to hear!'. The tone was clear. It was not friendly, and it had never been.

It has been a decade since the revision of Regulation 1049/2001 has been on the agenda, and no progress has been made. The Commission brought forward a new proposal in 2008. However, this proposal was extremely negatively received by the European Parliament (hereinafter 'EP') whose discontent was clearly expressed in its position. Indeed, in a resolution adopted by the EP on 15 December 2011 (which is still applicable at the time of writing in June 2018), the EP suggests more than 30 substantial amendments to the proposal put forward by the Commission. A comparison of the Commission proposal, on the one hand, and the EP's resolution on the other hand, helps us understand why reaching a consensus on a common instrument for public access to EU documents is proving so complicated.

\footnotetext{
${ }^{1}$ Mehmet Aktas received a bachelor degree in Law at Maastricht University in 2018. At the moment, he takes a Master in International and European Tax Law and a Master in Corporate and Commercial Law at Maastricht University, a Master in International Trade and Investment Law at the University of Amsterdam and a Master in Law, Markets and Behaviour at the Free University of Amsterdam. Contact: aktasm3838outlook.fr
} 
The aim of this paper is to contribute to the debate on the revision process of Regulation 1049/2001 by attempting to provide an explanation as to why the institutions have not agreed upon a viable solution yet. More specifically, this paper seeks to answer the following research question: Why have the Commission and the European Parliament been unable to agree on the revision of Regulation 1049/2001 on the right to public access documents since the entry into force of the Lisbon Treaty in 2008 until now?

The paper delves into three issues that are particularly problematic and that prevent the institutions to progress: (1) the overriding public interest test in relation to the exceptions laid down under Art. 4 ; $(2)$ the relationship between the right to public access to documents and the right to data protection; (3) the disclosure of documents originating from Member States. Methodologically, the paper combines juridical and political approaches.

The Commission's and the EP's positions are analysed because both are the central institutions involved in the legislative process and both made proposals for the revision of the Regulation. The Court of Justice of the European Union (hereinafter 'CJEU'), has also played a central role in the revision process, as this paper argues. The institutions are expected to follow the case law (Blauberg \& Schmidt, 2017, p. 907) and take it into account when legislating (Davies, 2016, p. 846). However, as argued below, the institutions' proposals are not always in line with the CJEU's judgments. In such instances, the judgments of the CJEU are still analysed but rather as a consultative institution instead of its traditional judicial role. As such, the CJEU's judgments are treated as mere institutional positions on given points.

This paper proceeds as follows. First, I sketch the historical background of Regulation 1049/2001 and the revision process. Secondly, I provide a literature review of the academic pieces on the topic of transparency and European public access to information. Then, the body of the paper is divided into three main parts. Each part is devoted to one of the components mentioned above. The conclusion draws the various lines of reasoning together.

\section{Historical Developments}

The entry into force of the Lisbon Treaty in December 2009 marked an important step in strengthening the democratic credentials of the European Union's institutions. The Lisbon Treaty has even added a section to the Treaty on the European Union (hereinafter 'TEU') on democratic principles which are applicable to all areas involving Union action. Moreover, the Lisbon Treaty introduced various reforms aimed at consolidating the principles of good governance, transparency and open decision-making. Before these reforms, the TEU already contained a 'public right of access to documents held by the Union's institutions, bodies, offices and agencies' in Art. 15(3). The Charter of Fundamental Rights of the European Union (which by virtue of Art. 6(1) enjoys Treaty status) further provides for a right to access documents in Art. 42. However, it needs to be noted that this right of the Charter is limited concerning access to documents held by the EP, Council and Commission and thus provides a more restricted scope.

The principle of open decision-making and the right to access to documents as enshrined in Art. 15(3) of the Treaty on the Functioning of the European Union (hereinafter 'TFEU') were mainly implemented through Regulation 1049/2001. It appears from Art. 1(a) of this Regulation that its main governing principle is 'to ensure the widest possible access to documents'. Art. 4 then provides for four exceptions to this main principle which the institutions may rely upon to deny access to certain documents (Chalmers et al., 2014, pp. 414-415). However, in line with the principle of 'widest possible access', the CJEU held in its case law that these exceptions must be interpreted and applied narrowly (Case C-280/11 P Council $v$ Access Info Europe (2013), para. 30). 
Since the adoption of this Regulation, a body of case law has emerged in which the CJEU interpreted some of its provisions and raised some questions; the European Ombudsman has dealt with several complaints and other developments have taken place that made the reform of the Regulation necessary (Commission Proposal 2008/0090 (COD)). Accordingly, the EP adopted a Resolution on 6 April 2006 requesting the Commission to come up with proposals to amend the Regulation (EP Resolution (2004/2125(INI))). In its Resolution, the EP listed additional reasons for which it believes a revision of the Access Regulation is necessary. The most significant of these is that Regulation 1049/2001 only partially implements Art. 255 EC (Art. 15(3) TEU) (EP Resolution (2004/2125(INI)), para. B). The EP made recommendations to the Commission for a proposal.

In response, the Commission drafted a proposal for amendments on the $30^{\text {th }}$ of April 2008. The Commission also drafted an explanatory memorandum in which it explained the amendments it suggested. In its explanatory memorandum, the Commission addressed the EP's recommendations but turned down some of them. These rejections pinpointed the beginning of a profound disagreement between the Commission and the EP. In addition to addressing the EP's recommendations, the Commission proposed numerous changes to Regulation 1049/2001.

Upon publication, the Commission proposal faced severe criticism for encroaching upon the underlying principle of Regulation 1049/2001 (Adamski, 2009, p. 521), namely to ensure the widest possible access to documents (Diamandouros, 2008). At this stage, the EP adopted its position from the first reading. The strongly divergent views throughout the revision process of Regulation 1049/2001 are clearly apparent from the non-negligible clashes between the Commission proposal and the major amendments proposed by the EP.

At the time of writing, the position of the Council is needed to further proceed with this proposal. While the position of the Council is similar to that of the Commission, the disagreement with the EP persists and has led to a complete impasse. It has been years since the beginning of the debate regarding the revision of the Regulation started, yet the process has grinded to a complete standstill (European Parliament Legislative Train, 2018).

\section{Literature Review and Methodology}

\subsection{Literature Review}

As the right to access public documents is a derivation of the principle of transparency, the literature on the latter is explored to make the link between the right to access public documents and transparency clearer. In the last couple of years, transparency has received a lot of academic attention. Traditionally, two distinct approaches have marked the study of transparency. Some scholars have explored transparency from theoretical and normative points of view. Such scholarship notably includes the study of normative relationships between transparency and other principles derived from democratic governance such as participation, accountability and legitimacy (Birkinshaw, 2006; Buijze, 2013; Fenster, 2015; Fox, 2007; Gaventa \& McGee, 2013; Stiglitz, 1999). This first approach to the study of transparency has one minor shortcoming. It focuses on theory, at the expense of practical examples of the application of the principle of transparency (Fenster, 2015; Hansen et al., 2015; Meijer, 2013; Meijer, Curtin, \& Hillebrandt, 2012). These pieces are general and assess transparency from a theoretical point of view.

Other scholars have opted for another approach by conducting specific case studies. Such studies explore specific pieces of legislation, their implementation and practical effects on democratic principles such as public participation, accountability and legitimacy (Birkinshaw, 2010; Calland \& Bentley, 2013; Hazell et al., 2012; Hazell \& Worthy, 2010; Mendel, 2008). This second approach has been particularly 
instrumental to the understanding of public access to documents regimes and their practical effects on transparency-related democratic principles.

In line with this case-based approach, some scholars have studied the public right to access to EU documents that is governed by Regulation 1049/2001 (Abazi \& Tauschinsky, 2015; Buijze, 2013; Curtin \& Meijer, 2006; De Leeuw, 2003; Dunin-Wasowicz, 2010; Héritier, 2003; Komanovics, 2009; Lenaerts, 2004; Peers, 2001; Roberts, 2002). These studies are thus relevant for this paper since they pertain to public access to documents within the EU. However, in the cited pieces of work, Regulation 1049/2001 and public access to documents within the EU are treated as secondary issues. Recently, some important pieces were produced specifically dealing with the topic of this paper (Curtin \& Leino, 2016; Leino, 2011; Harden, 2009).

In 'Openness, Transparency and the Right of Access to Documents in the EU' Deidre Curtin and Päivi Leino (ADD YEAR) provide a background to the issue of public access to documents within the EU. It highlights the developments in the jurisprudence of the CJEU. The main idea of this policy document is that the CJEU has interpreted the right to access documents too narrowly. Then, in 'Just a Little Sunshine in the Rain: the 2010 Case Law of the European Court of Justice on Access to Documents' Päivi Leino (YEAR) analyses three judgments rendered in 2010 by the Grand Chamber of the Court of Justice (hereinafter 'CoJ'), being one of the courts making up the CJEU: the TGI case, the Bavarian Lager case and the API case. These three cases had particular significance for the future application of Regulation $1049 / 2001$ since they concerned the interpretation of some core articles of the Regulation.

My paper adds to the existing literature by focusing on the differences of the institutions' positions. The mentioned papers are used to establish the respective views of the institutions. However, the existing literature does not provide a comprehensive analysis of the divergent views of the institution. This paper attempts to fill this gap by taking a more holistic view and probing into the differences of opinion between the institutions involved and how these diverging views evolved. By tracing the revision process over a longer time frame, it is possible to see more clearly why public access is such a controversial issue and why the European institutions are having such a hard time reaching a consensus.

\subsection{Methodology}

This paper ultimately analyses two documents. First, the Commission proposal for a Regulation regarding public access to EP, Council and Commission documents (COM(2008)229). This document contains the proposed articles, as well as an explanatory memorandum. The Commission explains which reasons underlie its suggested amendments. This document is the primary source for the Commission's stance on the debate of public access to documents and is hence used throughout the paper in order to explain the Commission's position. The second central source is the EP legislative resolution of 15 December 2011 which indicates the amendments the EP wants to make to the Commission proposal. The jurisprudence of the CJEU constitutes the third main primary source.

The methodological approach used in this paper consists of a qualitative and textual analysis of the three sources. This paper aims to further the case-specific perspective on public access to documents within the EU. Since the positions of the two institutions are best understood via their proposals, an indepth textual analysis of these documents is the most appropriate technique to achieve the goals of this paper. The textual methodology serves to elaborate on the nuances in the literal wording of the legal provisions studied in this paper which consequently allows to shed light not only on the differences but also on the commonalities of the analysed documents. 


\section{Overriding Public Interest (hereinafter 'OPI')}

\subsection{Background to the OPI}

Exceptions to the access to public documents are common in all legal systems. However, such exceptions must usually be balanced against the right of citizens to have access to documents. The institution holding the requested document must establish which of the interests prevail. If there is a public interest which overrides the reason for exception, the institution must disclose the document. Yet, in most systems there are so-called 'mandatory exceptions'. The specificity of these exceptions is that no public interest may override them. These are exceptions which typically include the protection of national security, defence, international relations and the economic well-being of a country.

However, in light of the growing importance of the debate on transparency, accountability and by extension the public right of access to documents, the existence of mandatory exceptions has been questioned. Indeed, in the latest international instruments on access to public documents, mandatory exceptions no longer exist. The application of all exceptions must always be subject to the OPI test (Deirdre \& Leino, 2016, p. 6). This international trend is apparent from the 2009 Council of Europe Convention on Access to Official Documents, which all EU Member States have signed and some ratified (Deirdre \& Leino, 2016, p. 6). This Convention provides that all exceptions to the right to access (Art. 3(1)) must be balanced against a potential OPI (Art. 3(2)).

\subsection{Regulation 1049/2001}

The currently applicable EU public access to documents regime contains a list of exceptions to the obligation to disclose documents. Art. 4 enumerates these exceptions. Paragraph 1 provides that 'the institutions shall refuse access to a document where disclosure would undermine the protection of the public interest as regards: public security; defence and military matters; international relations; the financial, monetary or economic policy of the Community or a Member State.'

Similarly, Art. 4(2) provides a list of situations where institutions must refuse access to a document. These exceptions relate to situations where the disclosure of a document would undermine the protection of commercial interests of a natural or legal person, including intellectual property rights, court proceedings and the purpose of inspections, investigations and audits. However, a fundamental difference exists between Art. 4(1) and 4(2). In the latter, the interests in non-disclosure of documents must be balanced against a potential OPI. This means that if there is an OPI in the disclosure of a document, the undermining of the listed interests is irrelevant and the document must be disclosed. In contrast, Art. 4(1) makes no room for an OPI test. This paragraph contains mandatory exceptions. If the disclosure is deemed to undermine the interests protected in that paragraph, access is denied and no balancing exercise with another interest at stake takes place.

Art. 4(3), like Art. 4(2), provides a balancing of interest mechanisms. The provision provides a list of documents whose disclosure can be refused if disclosure would seriously undermine the decision-making process of an institution. However, this is qualified by the possibility that such interest is overridden by an OPI.

\subsection{The Commission's proposal}

The Commission and EP have differing views on the issue of the OPI. The Commission proposes to adhere to the current regime in its reform proposal with few amendments. One amendment relates to the form of the article. In the current Regulation, the OPI is mentioned in Art. 4(2), 4(3) and 4(4). In the Commission 
proposal, the reference to the fact that the OPI applies to exceptions under Art. $4(2)$ and $4(3)$ is only expressed in Art. 4(4).

Moreover, while keeping the current regime, the Commission has provided clarification on situations which are considered to constitute an OPI. The Commission adds in Art. 4(4) that an OPI is deemed to exist in cases relating to documents touching upon the commercial interests of a legal or natural person when the information relates to emissions into the environment. This is the only substantive amendment brought by the Commission proposal to the issue of the OPI. As a conclusion, the Commission fairly sticks to the current regime in this respect. Therefore, the OPI test only takes place under Art. 4(2) and 4(3) but not under Art. 4(1).

Furthermore, the OPI is also relevant with respect to the disclosure of personal data. In the current Regulation, the issue of personal data is not specifically dealt with. However, in Art. 4(5) of its proposal the Commission deals with the disclosure of personal data (this matter is addressed in more depth in a subsequent section). In Art. 4(5), the Commission provides that personal information shall be disclosed 'unless disclosure would adversely affect the persons concerned'. Thus, the Commission does not provide for an OPI test when personal data are involved.

\subsection{The EP's resolution}

The EP disagrees with the Commission on this matter. In its resolution, the EP also subjects the exceptions under Art. 4(1) to the OPI test besides Art. 4(2) and 4(3). Subjecting these exceptions to the test means that the EP considers that there might be an OPI in the disclosure of a document, even where the so-called 'mandatory exceptions' apply. Moreover, in Art. 4(4) of its resolution the EP specifies circumstances under which an OPI is deemed to exist. It provides that such an interest exists when a requested document 'relates to the protection of fundamental rights and the rule of law, the sound management of public funds, or the right to live in a healthy environment, including in terms of emissions into the environment'. Thus, the EP provides a far more extensive definition of an OPI. The Commission restricts its specification to cases relating to the disclosure of documents which touch upon the commercial interests of a legal or natural person when the information requested relates to emissions into the environment. In the Commission's proposal, apart from this quoted situation, the scope of the OPI is unclear. However, considering the insufficient clarification in Art. 4(4) as to what constitutes an OPI and its exclusion from Art. 4(1), the interpretation sought by the Commission is likely to be narrower compared to the interpretation sought by the EP.

Furthermore, if the list of elements which are deemed to constitute an OPI under Art. 4(4) is closely examined, the reasons for subjecting the exceptions under Art. 4(1) to the OPI test become apparent. Indeed, the interests listed under Art. 4(1) could even be considered to be of a higher rank (the protection of fundamental rights and the rule of law and the sound management of public funds). In most EU Member States, they have constitutional status (see for example, Clemons, p. 4). Thus, the EP expectedly provides for a balancing test against the exceptions listed under Art. 4(1). The EP thereby argues that the grounds stated are serious enough to justify the disclosure of documents even when the highest interests are at stake (those listed in Art. 4(1)).

Concerning the OPI involving personal data, the EP takes a different stance from the Commission. The EP deals with the disclosure of documents containing personal data in Art. 4(5), as well. The threshold chosen by the EP is that of 'harm to the privacy or integrity of the person concerned, therefore, personal data should not be disclosed if such harm occurs. The provision goes on by providing three sets of circumstances when such harm is not deemed to be established. The EP then provides that even when there is harm to the privacy or the integrity of the person concerned, personal data could nevertheless be 
disclosed if an OPI requires disclosure. The EP sees the possibility of public interest overriding the interest of a person in their privacy. Such possibility is inexistent in the Commission's proposal.

\subsection{The position of the CJEU}

The CJEU has ruled on two main elements of the OPI test. First, the CJEU has ruled that a three-step test must be carried out in order to find an OPI justifying the disclosure of a document (Joined Cases C-39/05 $\mathrm{P}$ and $\mathrm{C}-52 / 05 \mathrm{P}$ Sweden and Turco $\mathrm{v}$ Council). Although this is an important contribution to the OPI test, this three-step test has not found its way in either of the institutions' proposals. The second element is that the CJEU has asserted that OPI was not applicable with regards to the exceptions under Art. 4(1) (Deirdre \& Leino, 2016, p. 6). For example, in the Sophie In't Veld case where the protection of international relations (under Art. 4(1)(a)) was raised as an exception to the right to access, the Court explicitly referred to the fact that in respect to Art. 4(1)(a), the legislator had not foreseen a balancing of competing interests (Case T-301/10 In't Veld v Commission, para. 90). The Court thus explicitly removed the possibility to claim competing balancing interests for Art. 4(1). In this way, the CJEU upholds the status quo since the Regulation does not provide any possibility to find an OPI when an exception under Art. 4(1) is at stake. Therefore, the Court's position enables us to situate it closer to the Commission's proposal rather than the EP's resolution.

\subsection{Conclusion}

In conclusion, whilst the CJEU has been firm in maintaining mandatory exceptions and therefore exempting these exceptions from the OPI test, it could have taken the international developments on public access to documents into account in its interpretation of the Regulation. The CJEU would have facilitated the incorporation of the international standards which have been agreed upon by the Member States within the Council of Europe. If maintained, the Commission's proposal will create a conflict of threshold between the EU Regulation and the Council of Europe Convention. While the former upholds mandatory exceptions, the latter abolishes them. Given that all the EU Member States are signatories and some have ratified the Convention, conflicting views on the matter have emerged. This incoherence should have been considered by the CJEU while interpreting the Regulation. Therefore, while the Commission's proposal is closer to the case law of the CJEU, the EP's resolution reflects the developing international standards more, which the EU Member States have agreed upon. At this point, it is hard to tell which direction will be eventually preferred. However, a harmonization of standards will be needed in the near future.

\section{Protection of Personal Data}

\subsection{Background to the protection of personal data}

On 25 May 2018, the EU's General Data Protection Regulation (GDPR) became applicable. This instrument is the response to the growing (mis)use of personal data by private entities, and has in turn, generated a lot of debate. Data protection has been under the spotlight for several years now. Indeed, the development of online activities made the use of personal data very common on online platforms and concerns about the safe use of these data gained prominence over the last years (Goddard, 2017, p. 703).

However, awareness about data protection did not render the right to public access less relevant. Both rights are equally important. Indeed, both have fundamental right status. The right to data protection is incorporated in Art. 8 of the Charter of Fundamental Rights of the EU while the right to public access to documents is enshrined in Art. 42. Thus, the question arose as to which right should prevail in situations 
where citizens request documents that contain personal information. This is an example of a clash between two fundamental rights and the institutions need to find answers on how to settle such a conflict.

\subsection{Regulation 1049/2001}

In the current Regulation, the protection of personal data is governed by Art. 1(b). This Article states that 'the institutions shall refuse access to a document where disclosure would undermine the protection of privacy and the integrity of the individual, in particular in accordance with Community legislation regarding the protection of personal data.' The current legislation considers the protection of personal data as a mandatory exception. Consequently, where an institution considers that the protection of personal data is undermined, no OPI may enable the disclosure of the requested documents.

Regulation 45/2001 on data protection was negotiated at the same time as Regulation 1049/2001 on public access. The two instruments indeed take each other's existence into account (Recital 15 of Regulation No 45/2001 \& Recital 11 of Regulation No 1049/2001). In 2001, the EU legislator wanted to adopt two distinct pieces of legislation which would be compatible with each other: one dealing with transparency and the right to public access to documents and another covering the protection of personal data (Leino, 2011, p. 1235). However, despite the efforts to ensure compatibility, three important provisions still conflicted. First, Regulation 1049/2001 does not indicate any requirement of consent by the data subject, while Regulation 45/2001 does require it. Secondly, while Regulation 1049/2001 grants universal access to the information, Regulation 45/2001 only foresees granting information to the applicant. Lastly, Regulation 1049/2001 explicitly denies the duty to provide motivation reasons for one's request for the disclosure of documents, while Regulation 45/2001 does require such reasons.

Because of these conflicting provisions, the question arose as to how the different interests at stake should be balanced in the event of a clash. When balancing the interests, one compromise was to blank out personal data in documents that were disclosed to the public. This practice has received particular attention by the Commission and the CJEU as demonstrated below.

\subsection{The Commission's proposal}

The Commission modified the protection of personal data regime by shifting Art. 4(1)(b) to the new Art. 4(5) (Commission Proposal 2008/0090 (COD), p. 8). The Commission Article is greatly influenced by the famous Bavarian Lager case. This case concerned the relationship between Regulation 45/2001 and Regulation 1049/2001. It also involved the blanking out of names in documents to which public access was granted.

In its explanatory memorandum, the Commission has provided that Art. 4(5) has reformulated the Art. 4(1)(b) to clarify the relationship between Regulations (EC) No 1049/2001 and 45/2001 (Commission Proposal 2008/0090 (COD), p. 8). However, the Commission said this in relation to the judgment by the Court of First Instance (hereinafter ' $\mathrm{CFI}^{\prime}$ ). Later, the Commission appealed this judgment and the case was brought before the Court of Justice (hereinafter ' $\mathrm{CoJ}$ '). The latter annulled the judgment of the CIF and ruled substantially differently, therefore, the Commission's argument of reformulating the provision in accordance with the CJEU's jurisprudence is outdated. Despite this newer judgment, however, the Commission did not reformulate its proposed provision in accordance with the latest case law.

Moreover, the Commission has argued that the practice of blanking out names of persons acting in a public capacity was too restrictive and dealt with this in its reformulated Art. 4(5) (Commission Proposal 2008/0090 (COD), p. 4). The Commission Article reads as follows: 'Names, titles and functions of public office holders, civil servants and interest representatives in relation with their professional 
activities shall be disclosed unless, given the particular circumstances, disclosure would adversely affect the persons concerned $(\ldots)^{\prime}$. The Commission provides a broader scope to the right to public access involving personal data than the CoJ did in the Bavarian Lager case. Indeed, with Art. 4(5) certain personal data (names, titles and functions) are subjected to a presumption of disclosure. The traditionally hostile approach of the Commission seems to have softened with Art. 4(5).

\subsection{The EP's resolution}

The EP endorsed the provision drafted by the European Data Protection Supervisor (hereinafter 'EDPS') who entirely redrafted the Commission's Article. While the Commission specifies the types of personal data that may be subject to the disclosure obligation, the EP merely refers to 'personal data' without specification. This choice of wording is designed to encompass more than solely what the Commission lists as 'personal data'. Furthermore, the wording of Art. $4(5)$ is surprisingly negative as if the default rule is that personal data shall not be disclosed and disclosure is the exception. The provision reads as follows: 'Personal data shall not be disclosed if such disclosure would harm the privacy or the integrity of the person concerned'. The provision continues by listing three sets of circumstances where harm to the privacy and integrity of the individual is not deemed to be caused.

First, it is deemed that no harm is caused if the data relate solely to the professional activities of the person concerned unless, given the particular circumstances, there is reason to assume that disclosure would adversely affect that person. The EP thus agrees with the Commission that particular circumstances can give rise to adverse effects on persons concerned when some personal data is disclosed. The second situation where harm is not considered to be caused is when the data relate solely to a public person. However, the EP recognizes again the possibility that harm can be caused even where the data relate solely to a public figure. In this specific situation, the EP not only recognizes that harm can be caused when disclosure adversely affects the public figure in question, but also when it affects other persons connected with them. Lastly, harm is not deemed to be caused if the data have already been published with the consent of the person concerned. The provision ends with the already-mentioned issue of OPI. In this resolution, the EP abolishes mandatory exceptions and subjects all of them, including the protection of personal data, to the OPI test.

\subsection{The position of the CJEU}

The CJEU did not adjudicate on all the dimensions that are dealt with by the Commission and the EP in their respective proposals. However, throughout the years, the CJEU has been confronted with an important number of cases relating to the protection of personal data exception. The CJEU has ruled on different aspects of this exception which may not be directly reflected in the institutions' proposals. However, a closer look at the case law makes it possible to assess which of the two proposals comes closer to the CJEU'S interpretation of this exception. Moreover, after establishing the approach of the CJEU, the EDPS's input on the matter is assessed to put the institutions' respective positions into a wider perspective.

The CJEU has decided several landmark cases on the protection of personal data exception. However, the Bavarian Lager is particularly interesting given the attention it has received by the Commission. In its proposal document, the Commission has criticized the practice of blanking out names and other personal data of individuals acting in their professional capacity when access to a document is given to the public. Thus, specific attention is given to this case to comprehend whether the CJEU stands closer to the Commission or the EP. The Bavarian Lager case concerned access to the names of individuals who were acting in a professional setting and took part in a meeting with the Commission, an interest 
group and British officials. The case related to the instrument to be used. Was this situation to be governed by the public access to documents regime or by the Regulation on the protection of personal data? This question was relevant because the outcome would differ depending on the application of one instrument or another. The case pertained to five names that had been made invisible from the minutes of the meeting following two refusals by the attendees to consent to the release of their names and the failure of the Commission to join the three other individuals. The Commission justified its refusal to disclose the names by arguing that the applicant had not provided sufficient reasons for such a disclosure.

The General Court (hereinafter 'GC') annulled the Commission's decision. It held that the request by the applicant is covered by Regulation 1049/2001 and pursuant to Art. 6(1) of this instrument no justification is required for the request of a document. The Commission appealed this judgment. The Co] held that neither of the Regulations should be given prevalence over the other and both should be fully applied (Case C-28/08 P Commission v Bavarian Lager Co. Ltd, para 56). It ruled that the GC had failed to correctly interpret Article 4(1)(b) of Regulation 1049/2001 because whenever this provision applies, any undermining of the privacy and the integrity of an individual must be examined in conformity with the legislation on the protection of personal data and with Regulation 45/2001 particularly (Case C-28/08 P Commission v Bavarian Lager Co. Ltd, para 60). The CoJ further held that whenever a request is made pursuant to Regulation 1049/2001 for the disclosure of a document containing personal data, Regulation 45/2001 becomes fully applicable (Case C-28/08 P Commission v Bavarian Lager Co. Ltd, para 63).

Then, the CoJ somewhat surprisingly held that the Commission was correct in checking whether the data subjects had consented to the releasing of their personal data (Case C-28/08 P Commission $v$ Bavarian Lager Co. Ltd, para 75). This is surprising because while the CoJ advocates the full application of both instruments, it rules in favour of the consent requirement as provided in Regulation 45/2001, thereby giving prevalence to the protection of personal data over the right to public access. It follows from the Bavarian Lager case that the approach of the CJEU is closer to that of the Commission. However, in this case this statement cannot be voiced strongly because even the Commission did not give much prevalence to data protection at the expense of public access in its proposal. Therefore, whether the Commission or the EP is closer to the case law of the CJEU remains somewhat unclear. Hence, the CJEU has not been followed by either of the institutions in their position on the revision process concerning Article $4(1)$ (b) of the Regulation 1049/2001.

\subsection{The position of the European Data Protection Supervisor}

The EDPS has voiced opinions on several points of the Bavaria Lager case. The EDPS has sided with the judgment of the GC and Bavaria Lager (Leino, 2011, p. 1239) and held views that run openly against the reading of the CoJ. It criticized the approach of the Commission to be too strict. The EDPS held that in order to refuse access to information that include personal data, the 'actual harm to privacy' threshold is always necessary (European Data Protection Supervisor, 30 June 2010). Therefore, the EDPS claims that not having the consent of the data subjects is not sufficient a ground for denying access to documents. Actual harm must exist in order to justify such refusal.

Moreover, although the Commission's proposal has favoured openness in situations involving the protection of personal data more than the CoJ in the Bavarian Lager case, the EDPS has been critical of Art. 4(5) proposed by the Commission for not doing justice to the need for a balanced approach between the right to public access and the right to personal data protection. The EDPS held that simply referring to Regulation 45/2001 might comply with the right to data protection but certainly not with the right to public access (European Data Protection Supervisor Opinion, 2009, para. 37). Thus, the EDPS advocates for a 'balanced approach' between the two rights. The EDPS's position thus reflects the approach of the GC in 
the Bavarian Lager case on the issue of privacy. Moreover, the EDPS was of the opinion that the Commission's suggestion that only names, titles and functions should be disclosed and reassessed and that restricting personal data to the three listed elements was too restrictive. Consequently, the EDPS drafted a provision on the protection of personal data. This provision was endorsed by the EP (European Parliament Resolution, 2009, amendments 90, 96 \& 102) and has been explained above.

Lastly, in light of the CJEU ruling in the Bavarian Lager case where the relationship between the two Regulations was somewhat blurred, the EDPS declared that the relationship between the right to public access to documents and the right to the protection of personal data needs to be clarified and reviewed as a matter of urgency (European Data Protection Supervisor, 30 June 2010). Since the rules on the protection of personal data have recently been reviewed with the introduction of the GDPR, the review of the relationship between this new instrument and Regulation 1049/2001 could be speeded up.

\subsection{Conclusion}

From the positions of the institutions and the opinions of the EDPS, it appears that a more comprehensive review and clarification of the relationship between the right to public access and the right to personal data protection is urgently needed. The Bavarian Lager case has been decisive on the interpretation of the relationship but it has failed to settle the issue satisfactorily. The Commission proposal is in line with the final judgment of the CoJ while the proposal by the EDPS (endorsed by the EP) reflects the approach of the GC in first instance. The latter emphasises the need to provide a fair balance between the two rights and not overly favouring the right to data protection so as to deprive the right to access of its essence.

\section{6) Documents originating from Member States}

\subsection{Background to the issue of documents originating from Member States}

The disclosure of Member States' documents by EU institutions is a difficult issue because it allocates to the EU institutions the power to decide on matters involving Member State information. The EU institutions have never been explicitly empowered to disclose Member State documents. Therefore, Member States rightly argue that they should have a say in the disclosure process of their documents. There is consensus amongst the different stakeholders on the fact that Member States should indeed have a say in the process. The extent to which Member States should influence the process is more controversial. The question relates to whether Member States should have a veto right on the disclosure of Member States documents or whether they should merely have a consultative role in which case the ultimate decision to disclose would lie with the EU institution holding the document. The institutions have approached the matter in different ways in their proposals and positions.

\subsection{Regulation 1049/2001}

The current regime deals with documents originating from Member States in Art. 4(5). It provides that ' $A$ Member State may request the institution not to disclose a document originating from that Member State without its prior agreement'. This provision indicates that the Regulation is granting Member States a right to veto the disclosure of any document originating from them.

\subsection{The Commission's proposal}

The Commission suggests to replace Art. 4(5) with a new Art. 5(2). Its provision reads as follows: 'The institution holding the document shall disclose it unless the Member State gives reasons for withholding it 
based on the exceptions referred to in Art. 4 or on specific provisions in its own legislation preventing disclosure of the document concerned. The institution shall appreciate the adequacy of reasons given by the Member State insofar as they are based on exceptions laid down in this Regulation.' The Commission is thus granting a veto right to Member States since they may rely on their national legislation to prevent the disclosure of documents. In such cases the institution cannot appreciate the 'adequacy of reasons given by the Member State' because the latter does not rely on the exceptions laid down in the Regulation (Harden, 2009, p. 251).

There are two elements in the article proposed by the Commission which deserve special attention insofar as they greatly limit its scope. First is the use of the conjunction 'or', and second is the word 'appreciate' in the second sentence of the provision. The conjunction 'or' limits the scope of the provision because it enables the Member States to invoke their own legislation as a justification for the refusal of the disclosure of documents. Member States are thus not bound by the exceptions under the Regulation but they rather enjoy tremendous discretion. This is likely to destroy the essence of the provision since

Member States will be able refuse the disclosure of documents as they see fit by invoking national legislation.

Secondly, the use of the verb 'appreciate' strengthens Member States' power to prevent disclosure of documents. In situations where Member States do not rely on national exceptions, but on those laid down in the Regulation, the mere appreciation of the adequacy of reasons does not give the institutions much power to resist a Member State's 'request' to withhold a document. Consequently, this provision gives Member States a full veto power against the disclosure of documents originating from them. The Commission seems to draw its inspiration from the case law of the CJEU for this provision. In the Sweden (IFAW) v. Commission case, the CJEU indeed ruled on this matter as follows: 'there is nothing to exclude the possibility that compliance with certain rules of national law protecting a public or private interest, opposing disclosure of a document and relied on by the Member State for that purpose, could be regarded as an interest deserving of protection on the basis the exceptions laid down by the Regulation.'

This paragraph in the CJEU's judgment indicates that national law could be relied upon when deciding on the disclosure of a document originating from a Member State. However, right before the quoted paragraph, the CJEU clearly explained that Member States may only rely on the exceptions listed in the Regulation under Art. 4(1)-(3). Moreover, the CJEU made it explicit that Member States should confine themselves to the exceptions available under the Regulation. Thus, the Commission's article only incorporates a distorted reading of the CJEU's interpretation of Art. 4(5).

\subsection{The EP's resolution}

Art. 5(2) as amended by the EP differs from the one suggested by the Commission in three fundamental aspects. First, the EP provides that 'the authorities of that Member State shall be consulted where there is any doubt as to whether the document is covered by one of the exceptions'. The novelty in this article lies in the fact that consultation of the authorities of the Member States is no longer automatic and mandatory. Indeed, only when there is doubt as to the application of an exception is there a need to consult the Member State authorities. Where there is no doubt, the authorities do not need be consulted. This gives great power to the institution since it has discretion to assess whether any doubt exists on the application of an exception.

Secondly, the EP denies the possibility for Member States to rely on national legislation to prevent the disclosure of the documents in question. The Member States may only rely on the exceptions laid down in Art. 4(1)-(3) of the Regulation to prevent disclosure. As shown above, this position is closer to that taken by the CJEU in its case law. Third, whilst the Commission suggests that after Member States give 
reasons to prevent the disclosure of the documents in question, the institution appreciates the reasons given by the Member State, the EP takes a different stance. The EP allocates a much stronger role to the institutions and greatly restricts the discretionary power of the Member State. The EP takes the view that the institution shall 'take a decision on the basis of its own judgment as to whether the exceptions cover the document concerned'. Thus, instead of an 'appreciation role' as advocated by the Commission, the EP favours a stronger role for the institution to give a decision based on its own judgment. Overall, Art. 5(2) as amended by the EP gives less power to the authorities of the Member States to prevent the disclosure of documents originating from them and grants the institutions holding the documents more power to decide on whether those should or should not be disclosed.

\subsection{The position of the CJEU}

In a literal reading of Art. 4(5), the CFI ruled that whenever a Member State requests an institution not to disclose a document originating from it, the obligations of disclosure flowing from the Regulation are no longer applicable and public access to documents is then exclusively covered by domestic law (Case T168/02, IFAW Internationaler Tierschutz-Fonds v. Commission (2004), para. 61). However, this case went on appeal and the CoJ repelled this line of reasoning in its 2007 judgment. The CoJ ruled that 'whilst the Member State from which a document originates may request the institution in possession of that document not to disclose it under Art. 4(5) of the Regulation, it does not have a right of veto with respect to such disclosure, as the final decision is a matter for the institution' (Case C-64/05 P, Sweden (IFAW) v. Commission (2007), para. 50). This argument clearly contradicts that of the CFI. It points out that Member States only have the power to partake in the decision-making process of the institution in question with respect to the disclosure of documents. Therefore, the CoJ makes it explicitly clear that the Regulation does not grant a right of veto to Member States on this issue.

Furthermore, the CoJ declared that when a document originating from a Member State is requested, the institution in question and the Member State must start discussing the potential application of one of the exceptions laid down in Art. 4(1)-(3) (Case C-64/05 P, Sweden (IFAW) v. Commission (2007), para. 75-76). With this judgment, the CJEU greatly narrowed the extent of the potential veto power of Member States flowing from Art. 4(5) as it was interpreted by the CFI.

\subsection{Conclusion}

The CJEU has expressed that Art. 4(5) does not attribute a veto power to the Member States. Moreover, it has also been clear on the fact that national legislation cannot serve as an alternative to the exceptions listed under Art. 4 of Regulation 1049/2001. Consequently, the Commission has misinterpreted the judgment of the CJEU and thus proposed an article that is not in accordance with its case law. Meaning, the jurisprudence of the CJEU is closer to the EP's proposal than that of the Commission.

\section{7) Conclusion}

The purpose of this paper was to offer insight into the elements that prevent the revision of Regulation 1049/2001. The entry into force of the Lisbon Treaty in 2009 called for a revision of the Regulation, but nearly ten years later the revision is still nowhere. Through this paper, it became apparent that some fundamental divergences exist between the Commission and the EP on certain provisions of the Regulation. The comparison of the proposals reveal two totally opposite views on transparency and the right to public access to documents. On the one hand, the Commission tries to implement a public access regime which hinders the least efficient of its decision-making process. For the Commission, the limits of transparency 
and the right to public access to documents extend up to the point where the administrative burden caused by the right to public access slows down the efficiency of the decision-making process of the institutions. Thus, in its proposal, the Commission provides for a restricted framework of public access to documents. The EP, on the other hand, has consistently favoured transparency at all costs. The EP is willing to slow down the decision-making process for the sake of transparency if necessary. This is reflected in the resolution it has adopted. The EP has indeed proposed a resolution that provides a very broad scope to the right of access to documents.

These two conflicting views were discernible in the analysis of the previous sections. In its proposal, the Commission has maintained mandatory exceptions. The EP, on the other hand, has extended the OPI to all the exceptions. While the Commission has advocated for emphasis on the right to data protection, the EP has endorsed the position of the EPDS in claiming a more balanced approach between the two rights so that the right to data protection is not given hierarchical prevalence and the right to public access is respected. Finally, while the Commission secures a veto right to Member States and the possibility to justify a refusal of disclosure by relying on national law, the EP merely gives a consultative role to the Member States while leaving the final decision on disclosure to the institution holding the document.

Besides the Commission and the EP, this paper provided some insight into the jurisprudence of the CJEU. The purpose was to set the institutions' respective proposals into perspective, given that the jurisprudence of the CJEU ought to be followed. If the institutions have incorporated some interpretations of the CJEU, they have not exhaustively codified its case law into their proposals. Consequently, it cannot be argued that the CJEU's case law is very close to either institution. The Commission and the EP have rather adopted the interpretations of the CJEU on an ad-hoc basis, when their views on public access was represented in the CJEU's judgments.

This paper attempted to provide insight into some concrete provisions of the Regulation on which the Commission and the EP cannot agree. Consequently, the revision process of the Regulation is currently at a standstill and there is no real prospect of resuming the negotiations. For a decade, hardly any agreement has been reached by the institutions. Despite the changes that are needed to clarify the meaning and scope of the provisions, the institutions cannot move forward. This is undesirable as it creates uncertainty and many challenges are going to be taken to the CJEU for its interpretation. However, the priorities of the Commission seem to differ from those of the EP. These differences on the interests that should prevail have contributed to the deadlock of the revision process. However, the urgency of the situation should motivate the institutions to review their positions and serve as an impetus to resume the negotiations and make this decade-long deadlocked instrument a new face of transparency within the European Union. 